\title{
An estimation of water origins in the vicinity of a tropical cyclone's center and associated dynamic processes
}

\author{
Toshinari Takakura $^{1} \cdot$ Ryuichi Kawamura $^{1} \cdot$ Tetsuya Kawano $^{1} \cdot$ Kimpei Ichiyanagi $^{2}$. \\ Masahiro Tanoue $^{3} \cdot$ Kei Yoshimura ${ }^{4}$
}

Received: 9 August 2016 / Accepted: 8 March 2017 / Published online: 17 March 2017

(c) The Author(s) 2017. This article is an open access publication

\begin{abstract}
To clarify the time evolution of water origins in the vicinity of a tropical cyclone (TC)'s center, we have simulated Typhoon Man-yi (July 2007) in our case study, using an isotopic regional spectral model. The model results confirm that the replacement of water origins occurs successively as the TC develops and migrates northward over the western North Pacific. It is confirmed that, in this case, a significant proportion of total precipitable water around the cyclone center comes from external regions rather than the underlying ocean during the mature stage of a TC. Similar features can also be seen in the proportion of each oceanic origin to total condensation. Indian Ocean, South China Sea, and Maritime Continent water vapors begin to increase gradually at the developing stage and reach their peak at the decay stage when the TC approaches southwestern Japan. These remote ocean vapors are transported to the east of the cyclone via the moisture conveyor belt, a zone characterized by distinct low-level moisture flux that stretches from the Indian Ocean to the TC, and are further supplied into the inner region of the TC by inflow within the boundary layer associated with its secondary circulation. Since it takes time to undergo these two dynamic
\end{abstract}

Ryuichi Kawamura

kawamura.ryuichi.130@m.kyushu-u.ac.jp

1 Department of Earth and Planetary Sciences, Faculty of Science, Kyushu University, 744 Motooka, Nishi-ku, Fukuoka 819-0395, Japan

2 Faculty of Advanced Science and Technology, Kumamoto University, Kumamoto, Japan

3 Institute of Engineering Innovation, School of Engineering, The University of Tokyo, Tokyo, Japan

4 Atmosphere and Ocean Research Institute, The University of Tokyo, Tokyo, Japan processes, the delayed influence of remote ocean vapors on the TC appears to become evident during the mature stage.

Keywords Tropical cyclone $\cdot$ Water origin $\cdot$ Moisture transport · Oxygen isotope ratio

\section{Introduction}

There is still room for improved prediction of tropical cyclone (TC) intensity (e.g., Rappaport et al. 2009; RiosBerrios et al. 2014). Kaplan and DeMaria (2003) pointed out the important roles of the ocean, inner-core dynamics, and large-scale environmental interactions in TC intensity change. Many influential factors make it difficult to fully understand the mechanisms of TC development. Latent heating is one key factor in the prediction of TC intensity because it is a driving source of TC development. Proper understanding of how water vapor is imported into the TC inner system and contributes to latent heating within the system through condensation may be useful in reducing significant errors in the prediction of TC intensity. However, our understanding is still limited with regard to water circulation and budgets inside and outside the TC system.

Earlier studies on such water budgets have been conducted by Malkus and Riehl (1960), Kurihara (1975), and others. They showed that evaporation from the ocean in the inner core area was very small as compared to the net moisture flux convergence. More recently, Braun (2006) and Yang et al. (2011) evaluated water budgets in the inner cores of TCs based on high-resolution simulations with a 2-km horizontal grid size and indicated that the water vapor from the underlying ocean in the inner core area is a very small portion of the inward horizontal vapor import, and the net horizontal convergence of vapor constitutes a 
large part of the net condensation within the inner core. Thus, it is necessary to highlight the behavior of water vapor not only from the underlying ocean but also from the outer-rainband area to clarify the overall feature of the water circulation of TC. Secondary TC circulation must play a vital role in the transportation of vapor in the boundary layer into the vicinity of the TC's center. As indicated in Fig. 14 of Yang et al. (2011), attention is also given to the importation of substantial moisture from the surrounding oceanic environment beyond the outer-rainband area because a continuous moisture supply from the surrounding region appears to contribute to the intensification and persistence of TCs. Few studies have yet addressed how moisture is imported from the surrounding ocean into the TC system in terms of the macroscopic view, although, of course, the TC-related poleward transport of tropical moisture has been examined in association with the occurrence of extremely heavy rainfall in mid- and high-latitude continental regions (e.g., Stohl et al. 2008).

Very recently, Kudo et al. (2014) (hereafter K2014), using a Rayleigh-type global isotope circulation model (ICM) for Typhoon Man-yi (2007), learned that western North Pacific TCs have the ability to accumulate abundant moisture from remote tropical oceans through the interaction of a Rossby wave response to TC-induced heating with the background flow. They also showed that the vapor supply from remote oceans occupies a large proportion of the total precipitable water around the cyclone center when it approached Japan; they named this type of largescale vapor transport from the tropics into the TC system the moisture conveyor belt (MCB). The TC heating acts as a source of equatorial Rossby waves and their dispersive westward phase propagation can produce a low-level cyclonic gyre and westerly flow west of the heated area (e.g., Holland 1995; Katsube and Inatsu 2016). K2014 postulated that the MCB is formed when the induced westerly flow overlaps with low-level monsoon westerlies around the South China Sea.

Hegde et al. (2016) (hereafter H2016) further investigated the relationship between MCB formation and the TC intensity and track by performing sensitivity experiments that modified sea surface temperature (SST) distributions over the Indian Ocean and the South China Sea in order to validate the working hypothesis that the MCB may be an active player in facilitating the development and persistence of the TC itself. They found that while the MCB is interrupted over the South China Sea in warm SST occurrences, large-scale vapor transport into the TC system is systematically reduced, leading to both the attenuated intensity and eastward track shift of the cyclone.

The findings of K2014 and H2016 suggest the presence of a positive feedback process between TC intensity and the MCB under the dominance of the South Asian monsoon westerlies, hereafter called the TC-MCB feedback for convenience. When TC-induced heating excites Rossby waves over the western North Pacific, the MCB is organized in the lower troposphere from the Indian Ocean and South China Sea into the TC system through interaction with the background monsoon westerly flow. The well-defined MCB facilitates the import of water vapor into the TC system from remote oceans, thereby contributing to TC intensification. Intensification further strengthens the MCB through the Rossby wave response to diabatic heating.

However, the question of how remote water vapor is penetrated into the TC system via the MCB is not answered satisfactorily, even if the TC-MCB feedback mechanism should operate efficiently. Since the ICM used in K2014 is a two-dimensional global isotope circulation model, it cannot evaluate how the water vapor of remote ocean origin is transported three-dimensionally into the outer-rainband and inner-core regions, and then condenses there. Another serious problem is that the inner structure of the TC is not resolved because, in K2014, the ICM incorporates an external meteorological data set derived from a global atmospheric reanalysis with a horizontal grid of $1.25^{\circ}$ longitude by $1.25^{\circ}$ latitude. If we also consider the results of Fudeyasu et al. (2008), who observed the isotope ratios of precipitation and water vapor during the passage of a typhoon, we may, thus, underestimate the proportion of underlying ocean vapor to total precipitable water in the vicinity of the TC's center.

This study builds upon the research of K2014 to solve the aforementioned two issues and increase the reliability of TC-MCB feedback. We employed the isotopic regional spectral model (IsoRSM) developed by Yoshimura et al. (2010). The main objectives of our study are (1) to evaluate more precisely the import of water vapor from remote oceans into the TC system and associated condensate water amount within the system using the IsoRSM, and (2) to clarify in more detail what dynamic processes cause the transport of remote ocean vapor into the outer-rainband and inner core regions. The rest of the paper is organized as follows. We first give a brief description of the model used and the experimental design. Section 3 describes the simulated features of the TC addressed in this study. Section 4 is an examination of what dynamic processes are crucial for causing water vapor to be imported into the TC system from remote tropical ocean regions. A discussion and a summary are presented in Sects. 5 and 6, respectively.

\section{Model and experimental design}

We conducted a colored moisture analysis (CMA), developed by Yoshimura et al. (2004), to track the origins of water within the TC system. This method can help us to 
understand how water vapor from specific regions is remotely transported. Figure 1 illustrates the partition of the main tagged-water source regions in this study. This partition is almost the same as that in K2014, which makes it possible to properly compare between the ICM used in K2014 and IsoRSM results, and we exclude the continental region and the oceanic region with no relation to the MCB. To validate the IsoRSM results obtained by this study, we utilized the stable oxygen isotope ratio $\left(\delta^{18} \mathrm{O}\right)$ data of the precipitation observed on a daily basis, following the precedent established by Yoshimura et al. (2004).

\subsection{Numerical model}

To perform the CMA, we employed the IsoRSM (Yoshimura et al. 2010) in this study. The IsoRSM incorporated the isotopic processes for water vapor as tracers on the basis of the regional spectral model (RSM; Kanamitsu et al. 2005) developed by the Scripps Experimental Climate Prediction Center. The physical parameterization schemes used in this model include the relaxed Arakawa-Shubert scheme (Moorthi and Suarez 1992), the Chou radiation (Chou and Suarez 1994) schemes, the Noah land surface model (Ek et al. 2003), and the microcloud physics proposed by Slingo (1987). A planetary boundary layer (PBL) scheme is a nonlocal scheme (Hong and Pan 1996). The IsoRSM uses a spectral nudging technique (Yoshimura and Kanamitsu 2009; Kanamitsu et al. 2010) that improved the selective scale bias correction (SSBC) method (Kanamaru and Kanamitsu 2007) with regard to the proper treatment of the lateral boundary condition. To reduce the imbalance between mass and wind fields, (a) only the rotational part of the wind was used with a slightly stronger nudging, (b) only area-averaged temperature was corrected, and (c) boundary zones were narrowed from 23 to $5 \%$ of the sides of the domain in the improved nudging technique. It is noteworthy that isotope and water vapor fields are not spectrally nudged or corrected but are forced by thinner lateral boundary zones. The data used in this nudging are described in the next subsection.

The isotopic processes in the IsoRSM consider the thermodynamic equilibrium fractionation among water vapor, liquid, and ice (Majoube 1971a, b) for most of the phase transition and also the kinetic fractionation for surface evaporation from open water (Merlivat and Jouzel 1979) for condensation from water vapor to ice under supersaturation conditions below a temperature of $-20^{\circ} \mathrm{C}$ (Jouzel and Merlivat 1984) and for evaporation and isotopic exchange from liquid raindrops into unsaturated air (Stewart 1975). Refer to Yoshimura et al. (2010) for more detail.

To validate the IsoRSM simulations in this study, we used the stable oxygen isotope ratio $\left(\delta^{18} \mathrm{O}\right)$ data in the precipitation observed on a daily basis at two representative observation sites, Ishigaki $\left(124.2^{\circ} \mathrm{E}, 24.4^{\circ} \mathrm{N}\right)$ in the Okinawa Islands and Fukuoka $\left(130.4^{\circ} \mathrm{E}, 33.6^{\circ} \mathrm{N}\right)$ in southwestern Japan where western North Pacific TCs approach very frequently. These in situ observation data were available from July 9, 2006, to August 8, 2009, at Ishigaki and from July 17, 2012, to August 5, 2014, at Fukuoka. The values of $\delta^{18} \mathrm{O}$ are measured using a mass spectrometer (ThermoQuest, Delta S) at Kumamoto University in Japan. The analytical errors of the instrument utilized are less than $\pm 0.1 \%$ for $\delta^{18} \mathrm{O}$. Figure 2 displays scatter plots of the observed and model-simulated $\delta^{18} \mathrm{O}$ in precipitation when
Fig. 1 Partition of tagged-water source regions. Different colors represent different origins. The illustrated black rectangle designates the domain of the isotopic regional spectral model (IsoRSM)

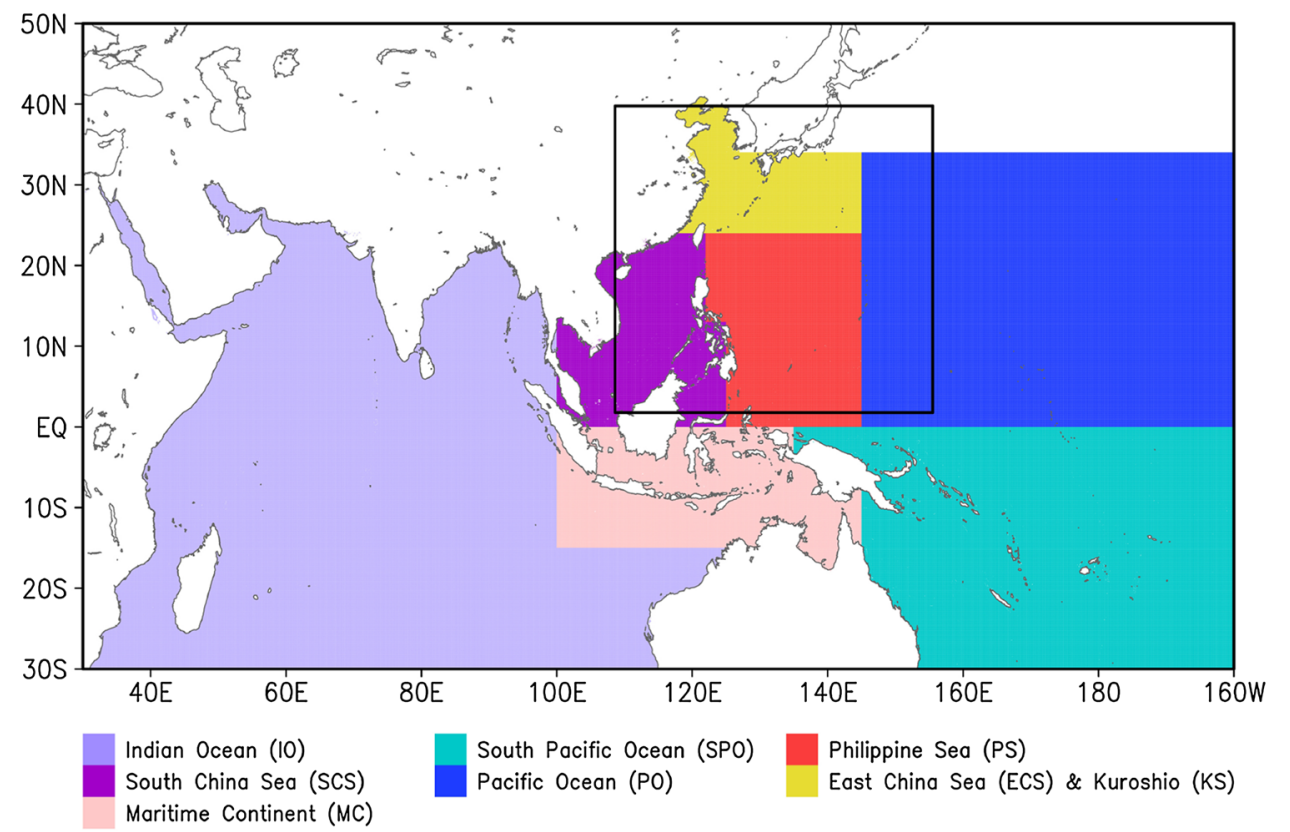




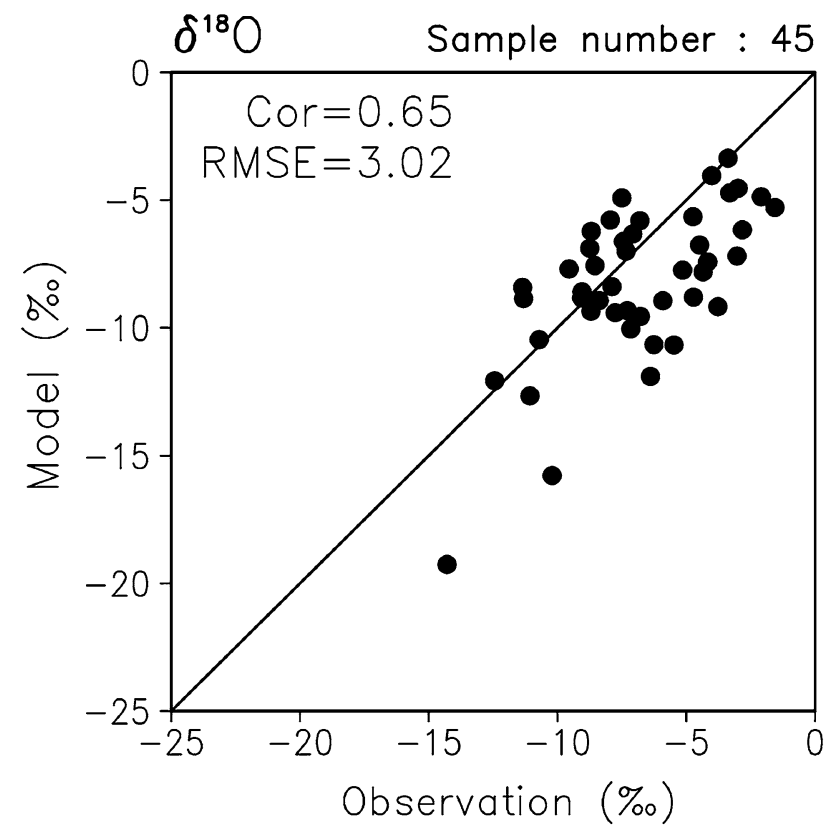

Fig. 2 Comparison of simulated and observed $\delta^{18} \mathrm{O}$ precipitation at Ishigaki in the Okinawa Islands and Fukuoka in southwestern Japan. Locations of these two observation stations are denoted in Fig. 3a

the TC center is located within a radius of $500 \mathrm{~km}$ from the observation sites, in consideration of a previous study by Tsuguti and Kato (2014), who determined that TCrelated precipitations roughly concentrate within a $500-\mathrm{km}$ radius. As a consequence, 26 TCs were subject to validation. The initial times of the IsoRSM simulations for the validation were set 3 days or more prior to each observation date. Although the data sampling is not large enough, due to a shortage of observations, the correlation coefficient and root-mean-square error obtained are comparable to the results of previous research (e.g., Ichiyanagi et al. 2005) that validated the $\delta^{18} \mathrm{O}$ in precipitation. The correlation coefficient satisfies a $1 \%$ level of statistical significance. These results suggest that the IsoRSM successfully captures the basic nature of the water vapor distribution within the TC system. Tanoue et al. (2016) also pointed out that the IsoRSM with a horizontal resolution of $10 \mathrm{~km}$, which is the same as the model used in this study, showed good reproducibility of the spatio-temporal variation of the isotopic composition of precipitation due to a TC around Japan.

\subsection{Experimental design}

We targeted Typhoon Man-yi (2007), which is the same typhoon as that studied in K2014 and H2016, to compare the model's results with previous results. Man-yi formed as a tropical depression over the western North Pacific Ocean on July 8, 2007. The storm gradually built in power to typhoon status on July 10 and approached southwestern Japan across the Okinawa Islands. Model integration was performed over the period from 0000UTC on July 6 to 1800UTC on July 16, 2007. The model domain is East Asia and the northwestern Pacific sector $\left(108.604^{\circ} \mathrm{E}-155.527^{\circ} \mathrm{E}, 1.772^{\circ} \mathrm{N}-39.773^{\circ} \mathrm{N}\right)$, as indicated in Fig. 1. We selected 7-km horizontal resolution and 28 vertical sigma levels. The time step is $20 \mathrm{~s}$. The lateral boundary and initial conditions were taken from the model output that contained information on the isotope and the colored moisture that was simulated by the isotopic global spectral model (IsoGSM; Yoshimura et al. 2008). The initial time of the IsoGSM was set 2 months before the time of the IsoRSM. The IsoGSM also employed a modified version of the SSBC method as a spectral nudging technique that corrects temperature and horizontal wind at all layers and all time steps [see Yoshimura and Kanamitsu (2008) for details]. To reduce large-scale biases, the dynamic field of a scale larger than $500 \mathrm{~km}$ was nudged, using the Japanese 55-year reanalysis (JRA-55; Kobayashi et al. 2015). We should note again that isotope and water vapor fields are not spectrally nudged or corrected.

We utilized sea surface temperature and sea ice distribution from the National Oceanic and Atmospheric Administration Optimum Interpolation Sea Surface Temperature V2 (NOAA OISST V2; Reynolds et al. 2002) as surface boundary conditions of the IsoRSM and the IsoGSM.

\section{Overview of the simulated TC}

\subsection{TC intensity and track}

Figure 3 compares the simulated TC intensity and track with those observed. Observations are based on the best track data provided by the Regional Specialized Meteorological Center of Tokyo-Typhoon Center. Overall, the simulation shows good correspondence with observations. The simulated track coincides well with the observed one; however, the time evolution of the simulated TC intensity in terms of central pressure is somewhat different from that observed. Particularly, the time of the cyclone's maximum development tends to be delayed, as compared to observations. Hereafter, we focus specifically on 0000UTC on July 11,0000 UTC on July 12, 0000UTC on July 13, and 0000UTC on July 14, which are signified as A, B, C, and D, respectively. The labels A and B correspond to the developing stage of Man-yi, located over the Philippine Sea, whereas $\mathrm{C}$ and $\mathrm{D}$ correspond to its mature stage, located over the East China Sea. 

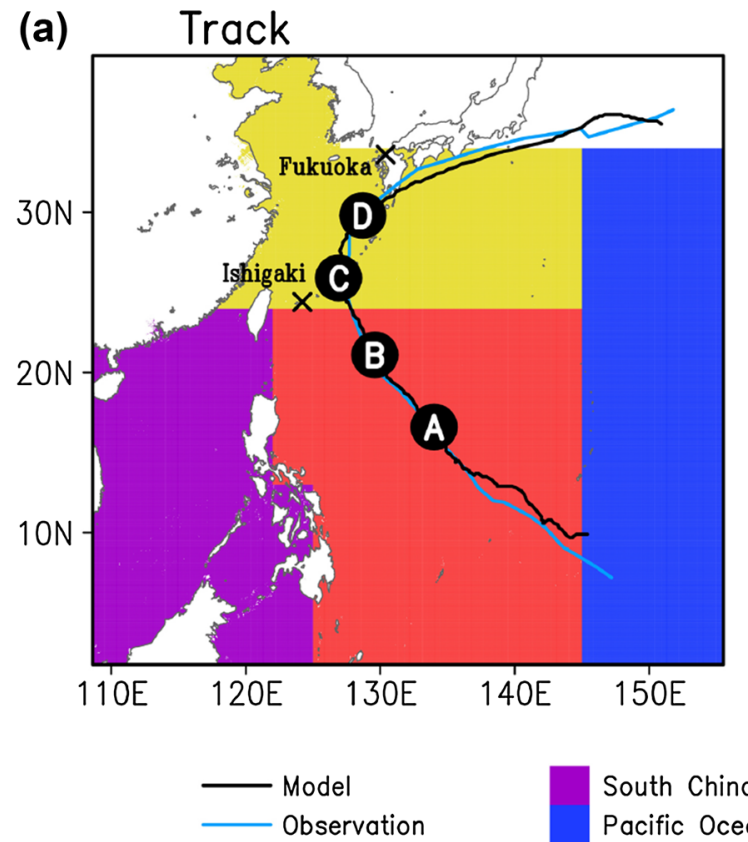

Fig. 3 Comparison between simulated (black line) and observed (light blue line) a track and b central pressure of Typhoon Man-yi (2007). Locations of the typhoon at 0000UTC on July 11, 0000UTC

\subsection{Simulated inner structures of the TC system}

Figure 4 displays the azimuthally averaged tangential and radial winds at the mature stage (0000UTC on July 13) of Man-yi. The simulated wind distributions are similar to the results of high-resolution simulations by Braun (2006), Yang et al. (2011), and others. The maximum value of the tangential wind reaches $54 \mathrm{~m} \mathrm{~s}^{-1}$ at a radius of approximately $65 \mathrm{~km}$. The inflow of radial wind concentrates in the boundary layer below $800 \mathrm{hPa}$, and the maximum value of the inflow is $13 \mathrm{~m} \mathrm{~s}^{-1}$ at a radius of approximately $70 \mathrm{~km}$, whereas the outflow is prominent in the upper layer above $400 \mathrm{hPa}$, and its maximum value is $15 \mathrm{~m} \mathrm{~s}^{-1}$ at $200 \mathrm{hPa}$ at a radius of approximately $110 \mathrm{~km}$. Since the size of the inner (b) Central Pressure

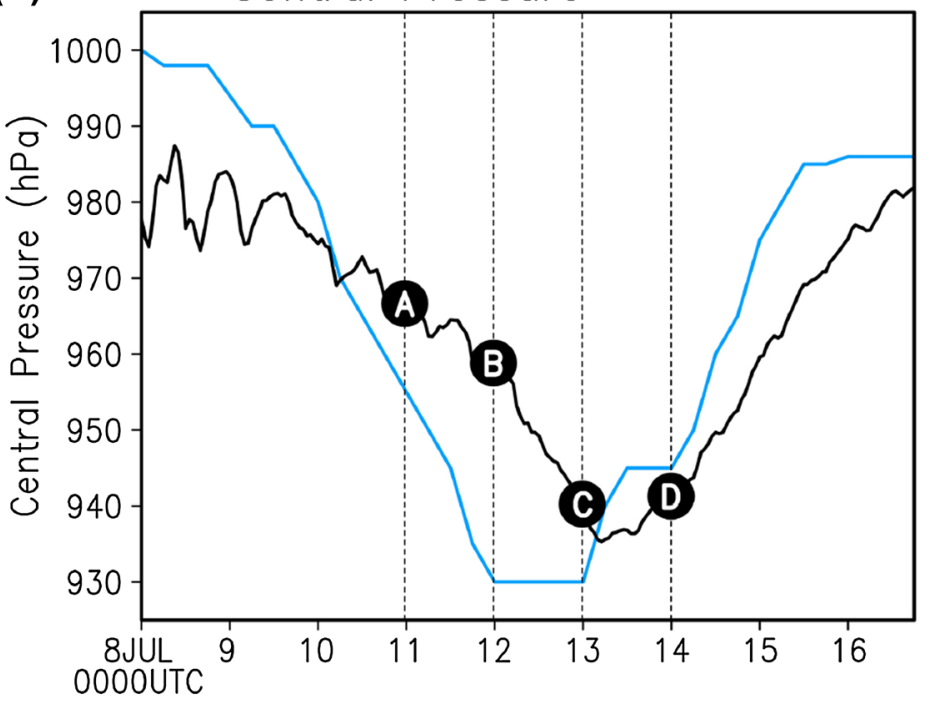

Philippine Sea (PS)

East China Sea (ECS) \& Kuroshio (KS) on July 12 , 0000UTC on July 13, and 0000UTC on July 14 are marked as $A, B, C$, and $D$, respectively

core is two or three times the radius of the maximum wind speed (e.g., Wang and Wu 2004; Wang 2009), we judged that the size of the inner core of the simulated Man-yi is roughly $130-190 \mathrm{~km}$. In this study, the vicinity of the TC center is defined as the domain within a radius of $200 \mathrm{~km}$ that covers the inner core for estimating the vapor import into the TC system.

Figure 5 indicates the distribution of precipitation intensity at each stage from A (0000UTC on July 11) to D (0000UTC on July 14). Note that a black circle in each panel denotes a radius of $200 \mathrm{~km}$ with respect to the TC center. Although the TC structure is unclear at the early developing stage, A, typical mesoscale structures, such as an eye wall and inner spiral rainbands, are rapidly (a) Tangential Wind

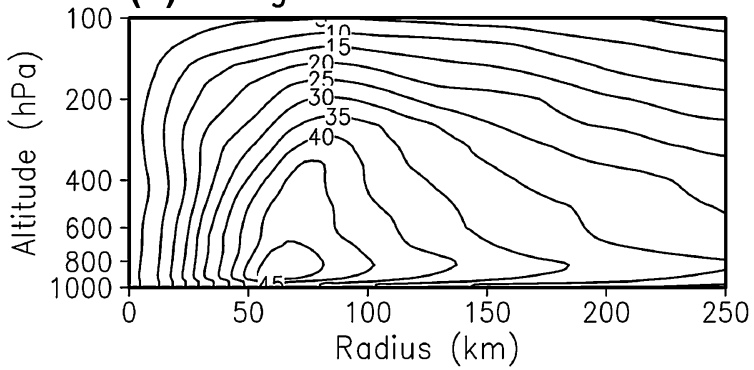

(b) Radial Wind

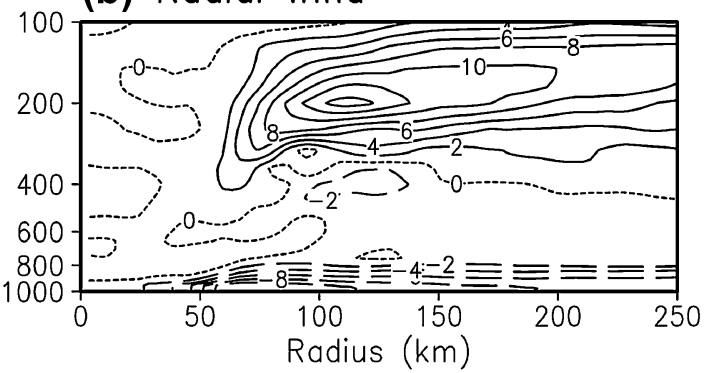

Fig. 4 Azimuthally averaged fields for a tangential wind and $\mathbf{b}$ radial wind at 0000UTC on July 13. The contour intervals for tangential and radial winds are 5 and $2 \mathrm{~m} \mathrm{~s}^{-1}$, respectively. Solid (dashed) lines for the radial wind denote outflow (inflow), and dotted lines are $0 \mathrm{~m} \mathrm{~s}{ }^{-1}$ 
Fig. 5 Magnified view of precipitation intensity (unit: $\mathrm{mm} \mathrm{h}^{-1}$ ) at a 0000UTC on July 11, b 0000UTC on July 12, c 0000UTC on July 13, and d 0000UTC on July 14 . The black circles denote the radius of approximately $200 \mathrm{~km}$, defined as the vicinity of the tropical cyclone center (a) 0000UTC 11 July

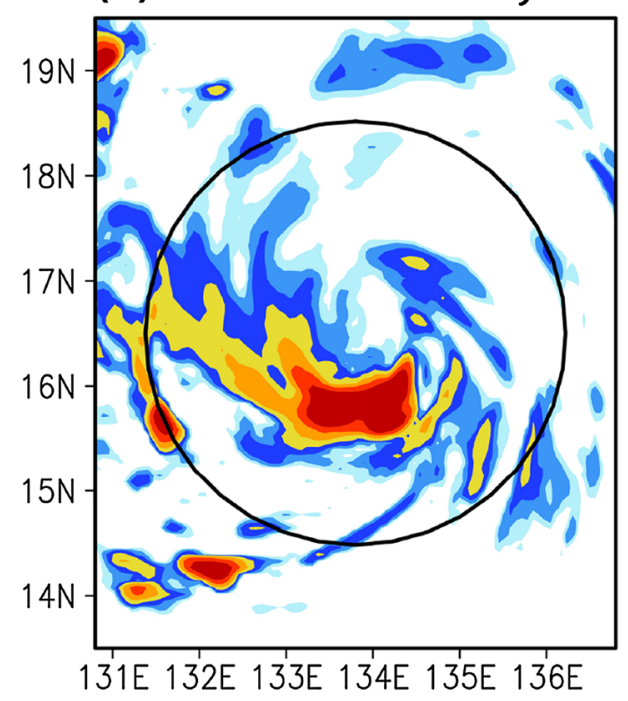

(c) 0000UTC 13 July

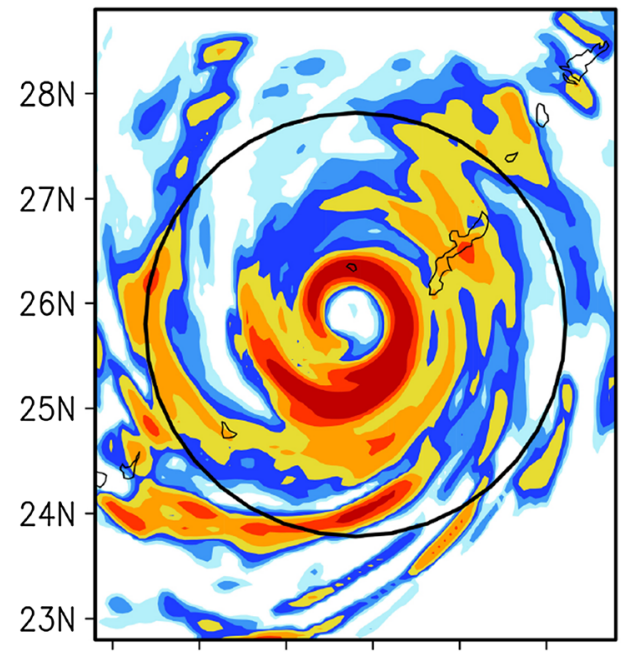

124E 125E 126E 127E 128E 129E (b) 0000UTC 12 July

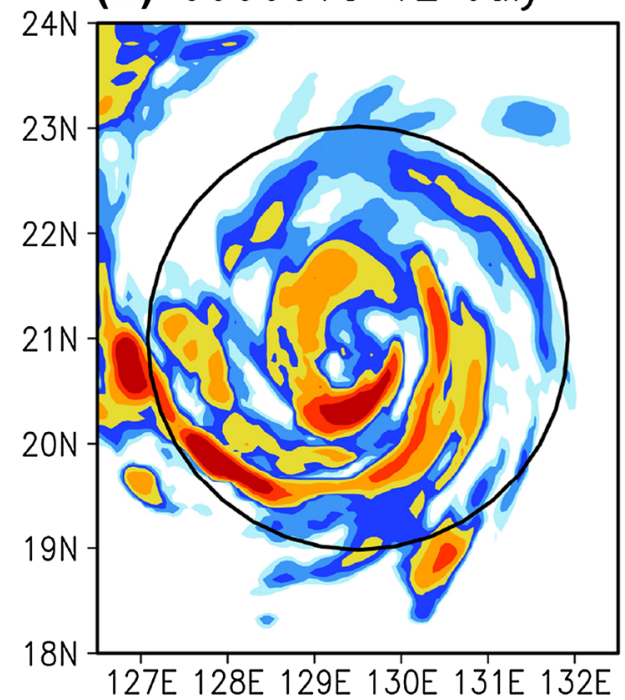

(d) 0000UTC 14 July

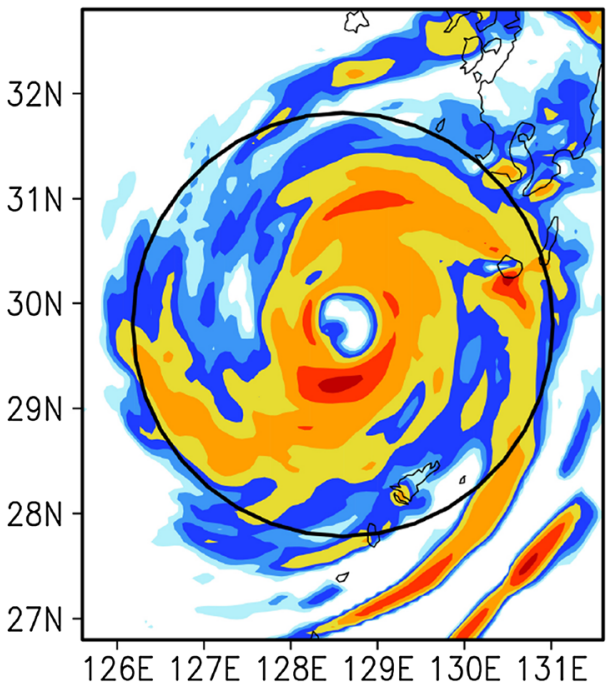

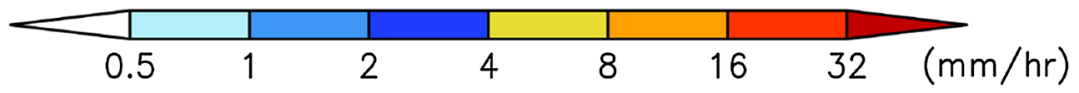

established from stage B to C. At the mature stage, D, the concentration of high precipitation intensity becomes somewhat obscure; however, central pressure in the TC is still very low, as shown in Fig. 3b. These features confirm that our simulation successfully captured the basic structures of the TC inner core as well as Fig. 4.

\subsection{Moisture conveyor belt (MCB)}

Figure 6 shows the spatial patterns of vertically integrated water vapor flux and surface turbulent latent heat flux at stages A, B, C, and D. As Man-yi migrated northward, a pronounced moisture flux zone stretched from the South China Sea into the vicinity of the TC center. K2014 referred to this zone as the moisture conveyor belt (MCB) and emphasized that the MCB plays a vital role in transporting large amounts of moisture into the TC system from the Indian Ocean and South China Sea regions. From stage A to B (Fig. 6a, b), the MCB is well organized, which is consistent with the result of $\mathrm{H} 2016$ (see their Fig. 6), which simulated the time evolution of the MCB in conjunction with the TC development. As shown in the lower panel of Fig. 6, surface turbulent latent heat fluxes are enhanced along the overlying MCB, mainly due to increased surface wind speed. This process is also expected to facilitate the importation of moisture into the TC system. According to H2016, when the MCB is ill organized over the South China Sea, the large-scale importation of moisture into the 
Water Vapor Flux

(a) 0000UTC 11 July

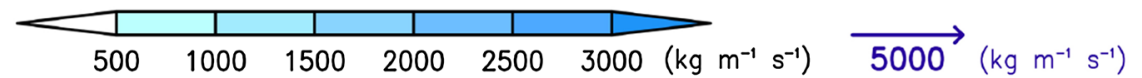

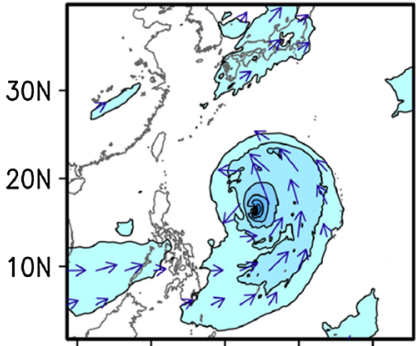

110E 120E 130E 140E 150E (b) 0000UTC 12 July

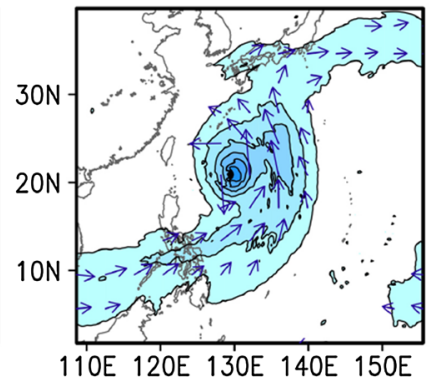

(c) 0000UTC 13 July

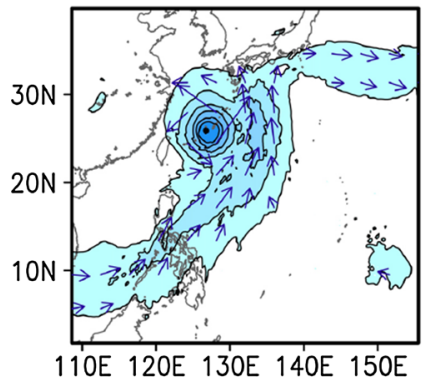

(d) 0000UTC 14 July

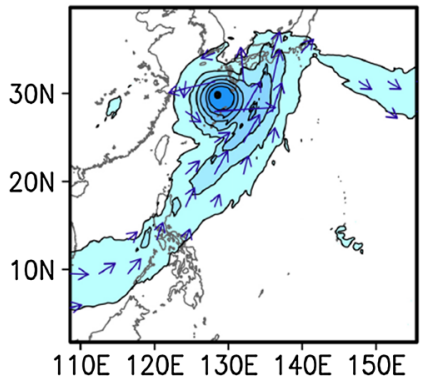

Latent Heat Flux

(e) 0000UTC 11 July

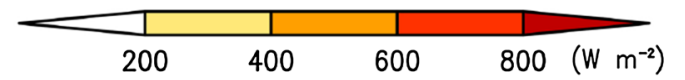

(f) 0000UTC 12 July
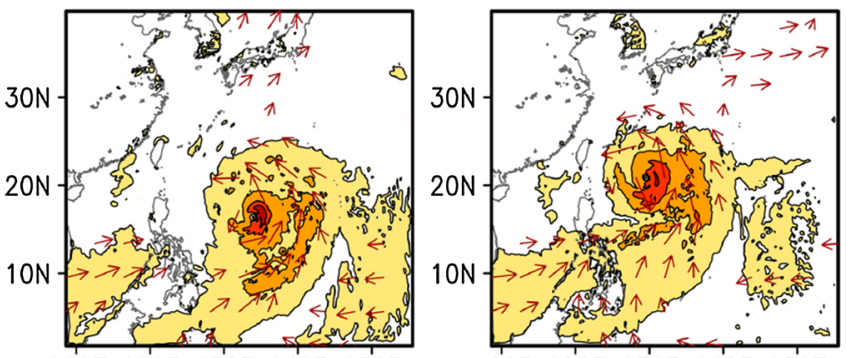

(g) 0000UTC 13 July
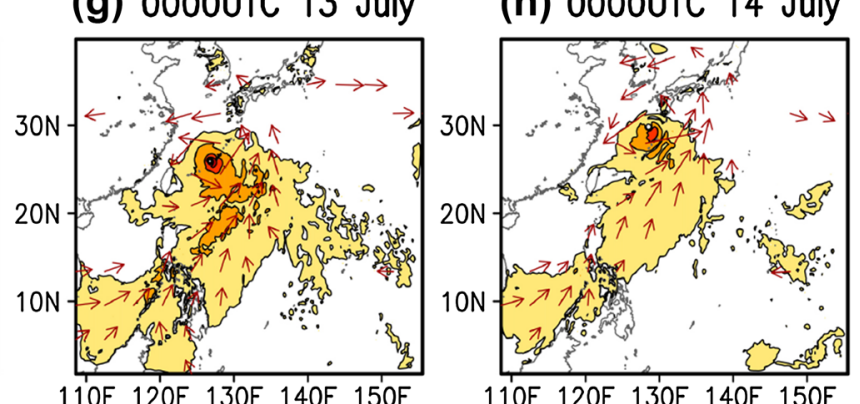

Fig. 6 (Upper panel) Spatial patterns of vertically integrated moisture flux (vectors) and its magnitude (shaded) at a 0000UTC on July 11 , b 0000UTC on July 12, c 0000UTC on July 13, and d 0000UTC on July 14. The reference arrow is $5000 \mathrm{~kg} \mathrm{~m}^{-1} \mathrm{~s}^{-1}$. Fluxes of less than $500 \mathrm{~kg} \mathrm{~m}^{-1} \mathrm{~s}^{-1}$ have been suppressed. (Lower panel) Spatial pat-

TC system is reduced, leading to the weakening of the TC intensity. Thus, better simulation of the MCB's behavior is required to examine how remote ocean vapor is transported into the TC inner region through the TC-MCB feedback process.

\section{Large-scale moisture import into the TC inner region}

\subsection{Water origins in the vicinity of the $\mathrm{TC}$ center}

Figure $7 \mathrm{a}$ shows the hourly evolutions of precipitation, horizontal convergence of vertically integrated moisture flux, and surface latent heat flux averaged over the domain within a radius of $200 \mathrm{~km}$ that covers the inner core. The time series of the central pressure is also shown. Precipitation reaches its maximum value during the period between stages $\mathrm{C}$ and $\mathrm{D}$. It is apparent that precipitation variations are mostly regulated by variations of the horizontal moisture flux convergence, where surface evaporation from the

terns of surface turbulent latent heat flux (shaded) and 925-hPa horizontal wind (vectors) at e 0000UTC on July 11, f 0000UTC on July $12, \mathbf{g} 0000 \mathrm{UTC}$ on July 13 , and $\mathbf{h} 0000 \mathrm{UTC}$ on July 14 . The reference arrow is $70 \mathrm{~m} \mathrm{~s}^{-1}$. Wind speeds of less than $10 \mathrm{~m} \mathrm{~s}^{-1}$ have been suppressed

underlying ocean is much smaller; this is consistent with the results of water budget analyses by Braun (2006) and Yang et al. (2011).

Figure $7 \mathrm{~b}$ depicts the hourly variations in the oceanic origins of total precipitable water averaged over the same domain. Note that different colors represent different origins in Fig. 1. Total precipitable water reaches its peak in excess of $80 \mathrm{~mm}$ just after stage $\mathrm{C}$, which coincides well with the deepening of the central pressure. As Man-yi develops to the east of the Philippines, most of the total precipitable water gradually becomes Philippine Sea (PS) vapor (red color) instead of Pacific Ocean (PO) vapor (blue color). During the mature stage (C and D), East China Sea (ECS) and Kuroshio (KS) vapors (yellow color) increase, whereas the PS vapor decreases as Man-yi migrates farther northward and approaches southwestern Japan. One of the most notable features is that remote ocean vapors, such as Indian Ocean (IO), South China Sea (SCS), and Maritime Continent (MC) vapors, begin to increase at stages $\mathrm{C}$ and $\mathrm{D}$, despite the fact that Man-yi continues to be far away from those regions. The precipitable water from IO, 


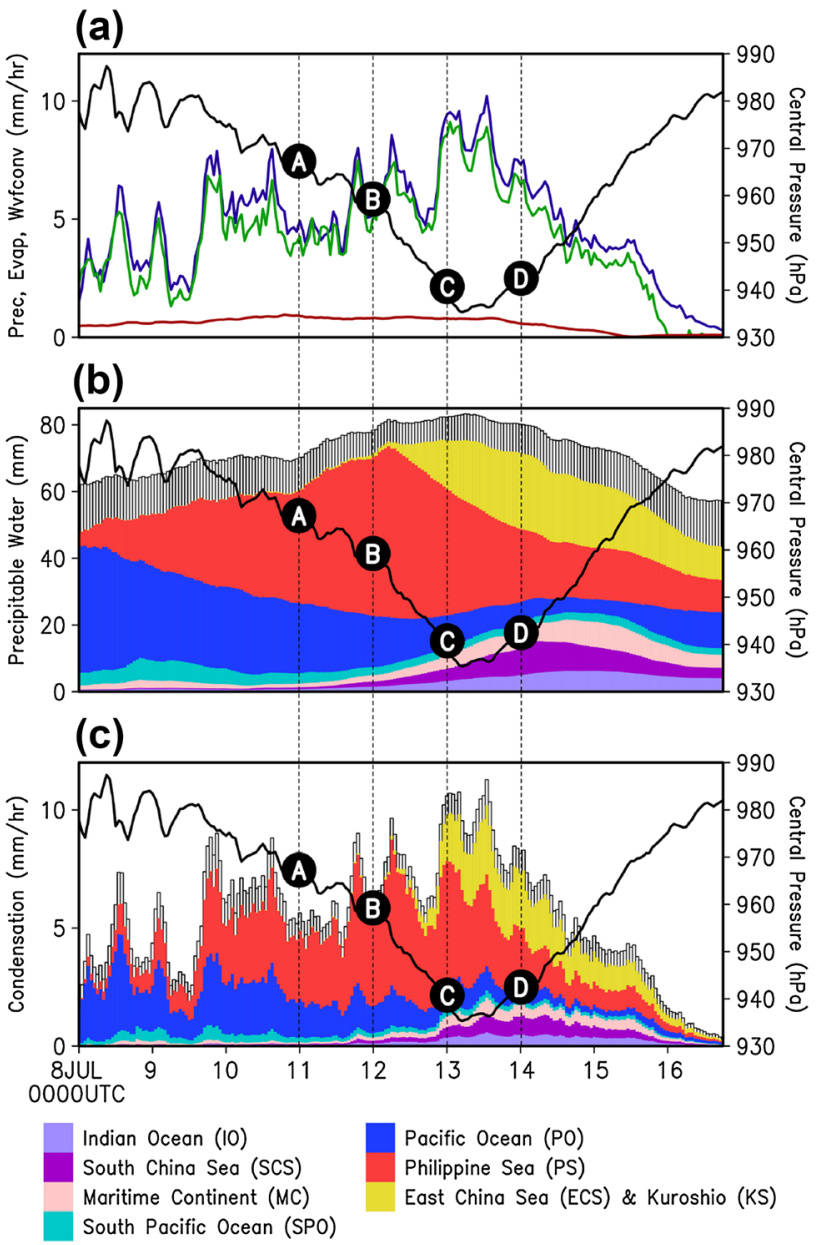

Fig. 7 a Hourly variations of rainfall (blue line), horizontal convergence of vertically integrated moisture flux (green line), and surface turbulent latent heat flux (red line) averaged over the domain in the vicinity of the center of Typhoon Man-yi. Unit is $\mathrm{mm} \mathrm{h}^{-1}$. The central pressure (black line) of the typhoon is also exhibited. Labels $A, B, C$, and $D$ designate the locations of the typhoon in Fig. 3a. b The same as in a but for the major oceanic origins (color bar) of total precipitable water (unit: $\mathrm{mm}$ ). Different color shadings denote variations in the different origins shown in Fig. 1. Variation in the central pressure is also denoted by a black line. $\mathbf{c}$ The same as in $\mathbf{b}$ but for the major oceanic origins (color bar) of total condensation (unit: $\mathrm{mm} \mathrm{h}^{-1}$ )
SCS, and MC vapors reaches its peak on July 14 , and its maximum value is approximately $22 \mathrm{~mm}$. This implies that a significant amount of vapor of remote ocean origins is imported into the vicinity of the TC center, which is consistent with the result of K2014. However, there are some differences between this study and K2014. A remarkable difference is that, in this study, the ECS and KO vapors are considerably larger than those of K2014. Since K2014 used an ICM with global atmospheric reanalysis data, the TC's mesoscale structure is not fully resolved, as mentioned in Sect. 1. Thus, it appears that K2014 underestimated the active evaporation from the underlying ocean due primarily to strong surface winds within the TC inner region. Of course, it is not very meaningful to discuss in detail all of the other differences between the two studies because their definitions of the vicinity of the TC center are different. We anticipate that the CMA results in this study are substantially improved as compared to those of K2014. Figure 7c is the same as in Fig. $7 b$ except for the oceanic origins of total condensation. It turns out that change in the proportion of each origin as Man-yi evolves is very similar to that of precipitable water, implying that remote ocean vapor can also exert influence on the TC intensity through the release of latent heat.

To more clearly identify the relative importance of each oceanic origin to the total precipitable water and condensation, we present in Table 1 the proportion of the major oceanic origins in precipitable water and condensation at stages A, B, C, and D. Since Man-yi is located over the PS sector during its developing phase (A and B), PS vapor occupies the largest proportion of all major origins. When the cyclone intrudes into the ECS and KS sector during its mature phase (C and D), the ratio of PS vapor decreases while that of ECS and KS vapor increases rapidly. On the other hand, the proportion of water vapors of the IO, SCS, and $\mathrm{MC}$ sector increases continuously from stage A to D. In stage D, the percentage reaches approximately $23 \%$, which is roughly comparable to that of PS vapor or ECS and KS vapors. If we simply define the remote ocean as

Table 1 Proportion of the major oceanic origins in precipitable water and condensation at stage A (0000UTC on July 11), B (0000UTC on July 12), C (0000UTC on July 13), and D (0000UTC on July 14)

\begin{tabular}{llllll}
\hline Time & $\begin{array}{l}\text { Indian Ocean (IO) } \\
\text { South China Sea (SCS) } \\
\text { Maritime Continent (MC) }\end{array}$ & $\begin{array}{l}\text { Pacific Ocean } \\
\text { (PO) } \\
\text { South Pacific } \\
\text { Ocean (SPO) }\end{array}$ & Philippine Sea (PS) & $\begin{array}{l}\text { East China Sea (ECS) } \\
\text { Kuroshio (KS) }\end{array}$ & Others \\
\hline 0000UTC 11 July & $3.4 \%(2.9 \%)$ & $34.2 \%(32.5 \%)$ & $48.4 \%(51.1 \%)$ & $0.4 \%(0.4 \%)$ & $1.5 \%(1.2 \%)$ \\
0000UTC 12 July & $6.3 \%(6.1 \%)$ & $22.6 \%(21.8 \%)$ & $60.8 \%(62.4 \%)$ & $8.8 \%(8.5 \%)$ \\
0000UTC 13 July & $13.1 \%(11.7 \%)$ & $14.5 \%(14.7 \%)$ & $45.8 \%(47.5 \%)$ & $17.8 \%(18.3 \%)$ & $8.8 \%(7.8 \%)$ \\
0000UTC 14 July & $22.6 \%(21.2 \%)$ & $10.9 \%(11.0 \%)$ & $27.4 \%(28.1 \%)$ & $28.4 \%(29.4 \%)$ & $10.7 \%(10.3 \%)$ \\
\hline
\end{tabular}

Numbers without brackets represent the ratio of precipitable water to the total. Numbers with brackets indicate the ratio of condensation to the total 
sectors, except for ECS, KS, and others, the proportion of precipitable water from remote oceans is approximately $61 \%$ at stage $\mathrm{D}$. This is also the case for condensation.

It is easy to understand that PO, SPO, and PS vapors decrease from stage $B$ to $D$ because Man-yi moves away from these regions. However, it is very interesting to note that water vapor from the IO, SCS, and MC sector, increases during the same period, which is consistent with the results of K2014. In order to clarify the reason, we will show the spatial distribution of each water origin in the next subsection.

\subsection{Spatial distribution of each water origin}

Since the proportions of major oceanic origins change largely in both precipitable water and condensation between stages B (0000UTC on July 12) and D (0000UTC on July $14)$, we specifically highlight these two stages. Figure 8 indicates the spatial distribution of the precipitable water of each oceanic origin at stages B and D along with the total precipitable water. Total precipitable water is abundant in the vicinity of the TC and along the MCB at both stages.
We can confirm that a large amount of moisture through the MCB comes from the IO, SCS, and MC regions. The vapors of these regions are already transported to the east of the TC system at stage B (Fig. 8b); however, they are not imported to the vicinity of the TC center. At stage D (Fig. 8f), however, these vapors have penetrated into the TC inner region. On the other hand, PS vapor occupies the largest part of the total precipitable water around the TC center at stage B (Fig. 8c) because it is located over the PS sector. As Man-yi approaches southwestern Japan, the PS vapor that Man-yi retained is rapidly consumed by active condensation, and then its proportion to the total precipitable water becomes similar to that of the other major oceanic origins at stage D (Fig. 8g). Another indication at the same stage is the presence of a meridionally elongated zone from the PS to the vicinity of the TC. Since evaporation at the ocean surface is enhanced along the MCB, as already shown in Fig. 6, it seems that PS vapor continues to be remotely supplied to the TC, even after it had moved away from the PS sector. As for ECS and KS vapor, surface evaporation from the underlying ocean near the TC center is pronounced at stage $\mathrm{D}$ (Fig. 8h).
O000UTC 12 July

(a) Total Precipitable Water
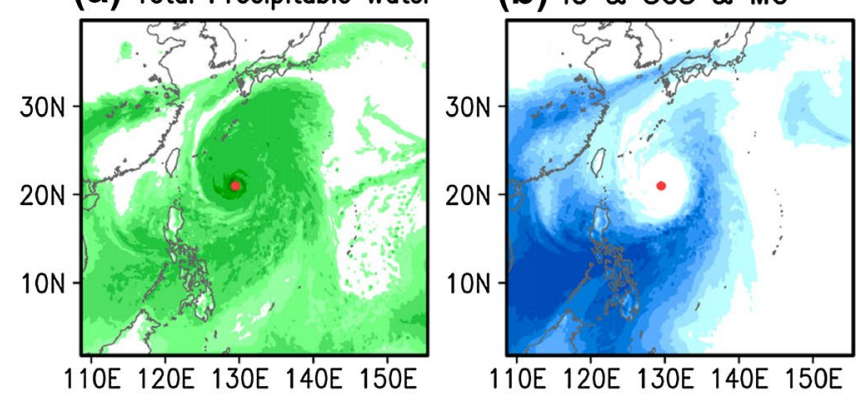

O000UTC 14 July

(e) Total Precipitable Water

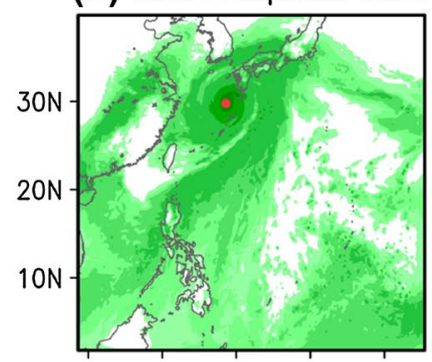

110 E 120E 130E 140E 150E

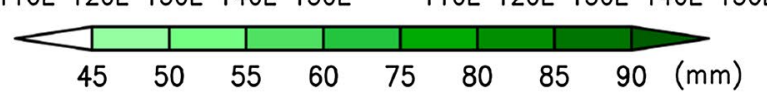

Fig. 8 (Upper panel) Spatial patterns of a total precipitable water, b Indian Ocean (IO), South China Sea (SCS), and Maritime Continent (MC) vapors, c Philippine Sea (PS) vapor, and d East China Sea (ECS) and Kuroshio (KS) vapors at 0000UTC on July 12. The shaded (c) PS

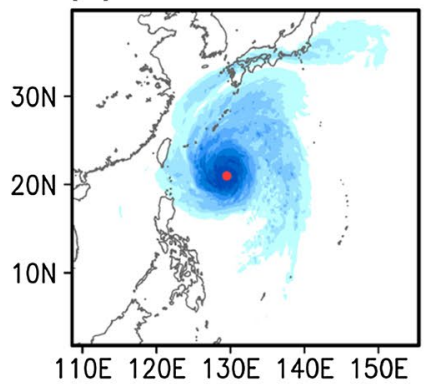

(d) ECS \& KS

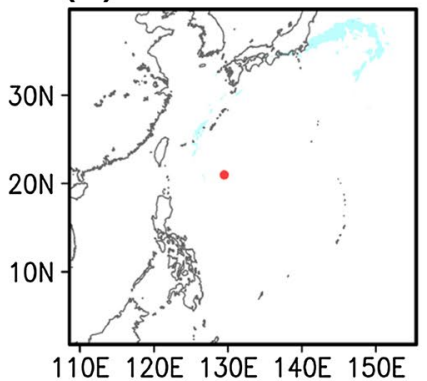

(h) ECS \& KS

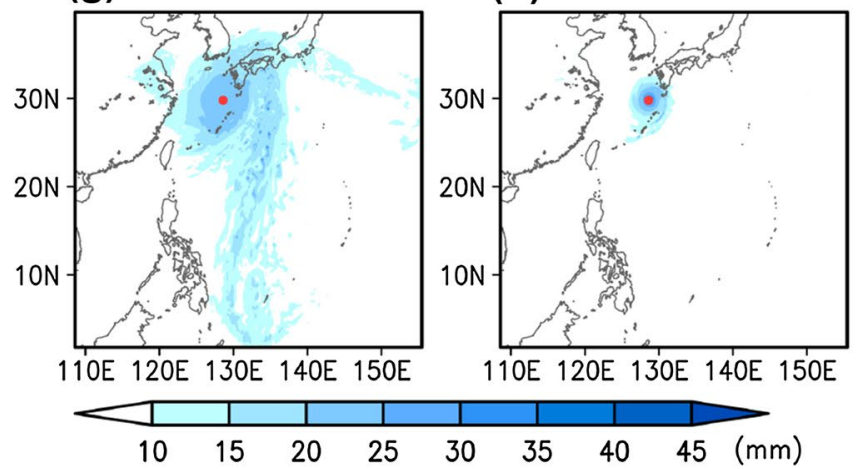

interval is $5 \mathrm{~mm}$. The location of Typhoon Man-yi is indicated by a red circle. (Lower panel) Spatial patterns of e total precipitable water, f IO, SCS, and MC vapors, $\mathbf{g}$ PS vapor, and $\mathbf{h}$ ECS and KS vapors at 0000UTC on July 14 
In a similar fashion, the spatial distribution of condensation of each oceanic origin at stages $\mathrm{B}$ and $\mathrm{D}$ is exhibited in Fig. 9, together with the total condensation. At stage B, TCrelated total condensation is primarily characterized by the condensation of PS vapor (Fig. 9a, c). At stage D, in contrast, the condensation of IO, SCS, and MC vapors occupies a significant part of the total condensation as well as that of ECS and KS vapors (Fig. 9f-h). These features are quite consistent with the information presented in Table 1 and Fig. 8, which suggests that Man-yi is maintained by a moisture supply not only from the underlying ocean but also from remote oceans, especially at stage D.

Although we demonstrated that at the stage B, the IO, SCS, and MC vapor has already been transported to the east of Man-yi via the MCB, it would be worthwhile to further account for how that vapor penetrates into its inner region from stages B to D. Thus, we present in Fig. 10 the azimuthally averaged specific humidity of the total and each oceanic origin at stages $\mathrm{B}$ and $\mathrm{D}$, along with tangential wind (contour) and radial and vertical wind (vector). At stage $\mathrm{B}$, the vertical distribution of the total specific humidity strongly reflects that of PS vapor (Fig. 10a, c), whereas at the stage $\mathrm{D}$, all three major oceanic origins of vapor contribute comparably to the distribution of the total specific humidity. If we look at the IO, SCS, and MC vapor (Fig. 10f), we find that it is imported toward Man-yi's inner core through the atmospheric boundary layer by radial inflow in association with the secondary TC circulation from stage B to D. The contribution of PS vapor becomes relatively small at stage D (Fig. 10g), as compared to that at stage B; however, we can infer that PS vapor still plays a significant role in the intensity of the TC. As for the ECS and KS vapor, its maximum is located at the near surface of the TC's center (Fig. 10h), indicating enhanced evaporation from the underlying ocean due to extraordinary strong winds within the inner core.

Figure 11 reveals the spatial distributions of 900- and 700-hPa specific humidities of IO, SCS, and MC origins at stages B and D. The 900- and 700-hPa levels were selected as representative heights in and above the
O000UTC 12 July

(a) Total Condensation

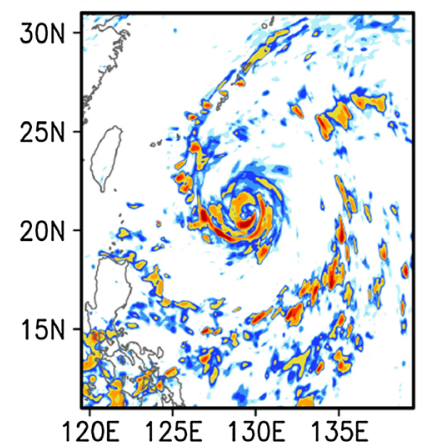

O000UTC 14 July

(e) Total Condensation

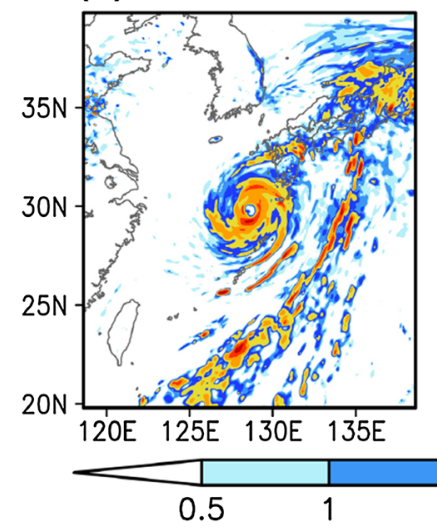

(b) $10 \&$ SCS \& MC

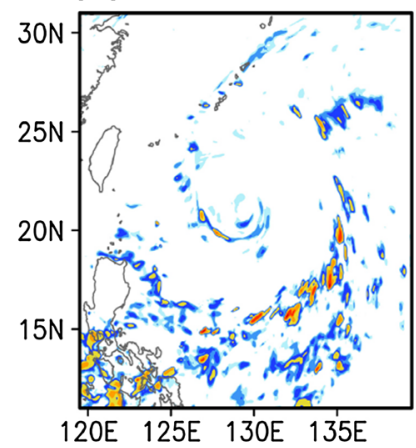

(f) $10 \& \operatorname{SCS} \& M C$

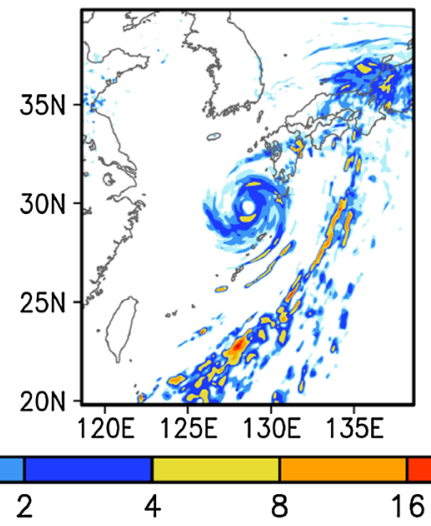

(c) PS

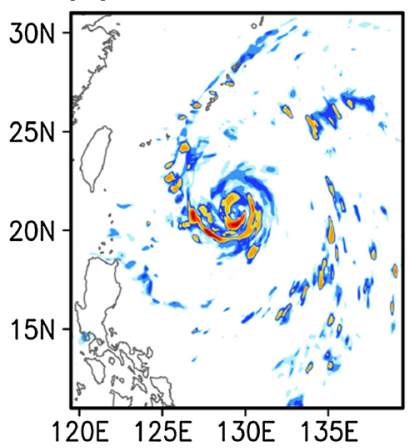

(g) PS

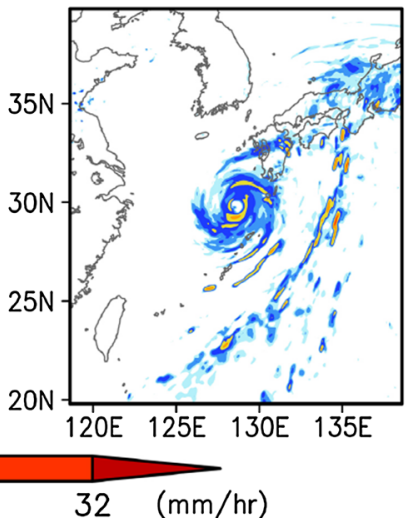

(d) ECS \& KS

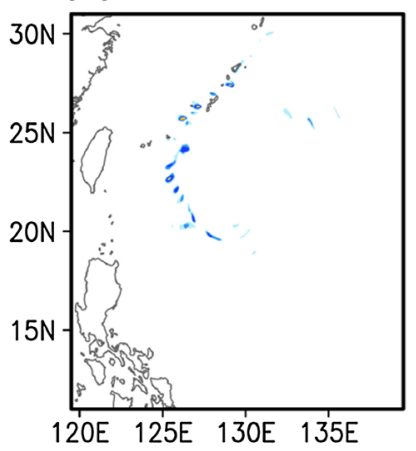

(h) ECS \& KS

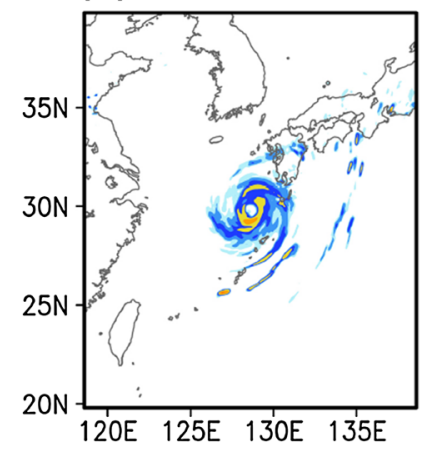

Fig. 9 (Upper panel) Spatial patterns of a total condensation, b Indian Ocean (IO), South China Sea (SCS), and Maritime Continent (MC) condensation, $\mathbf{c}$ Philippine Sea (PS) condensation, and d East China Sea (ECS) and Kuroshio (KS) condensation at 0000UTC

on July 12. (Lower panel) Spatial patterns of e total condensation, $\mathbf{f}$ IO, SCS, and MC vapors, $\mathbf{g}$ PS vapor, and $\mathbf{h}$ ECS and KS vapors at 0000UTC on July 14 
Fig. 10 (Left panel) Azimuthally averaged fields for a total specific humidity, b Indian Ocean (IO), South China Sea (SCS), and Maritime Continent (MC) vapors, c Philippine Sea (PS) vapor, and d East China Sea (ECS) and Kuroshio (KS) vapors at 0000UTC on July 12. Unit is $\mathrm{g} \mathrm{kg}^{-1}$. Azimuthally averaged fields for tangential wind (red contours) and radial and vertical wind (vectors) are also exhibited. The contour interval for the tangential wind is $5 \mathrm{~m} \mathrm{~s}^{-1}$. The reference arrow for the radial wind is $15 \mathrm{~m} \mathrm{~s}^{-1}$. To match the scale of the wind speed, we multiplied the vertical wind (unit: $\mathrm{Pa} \mathrm{s}^{-1}$ ) by a factor of 0.1. (Right panel) Azimuthally averaged fields for $\mathbf{e}$ total specific humidity, f IO, SCS, and MC vapors, $\mathbf{g}$ PS vapor, and $\mathbf{h}$ ECS and KS vapors at 0000UTC on July 14
O000UTC 12 July

(a) Total Specific Humidity

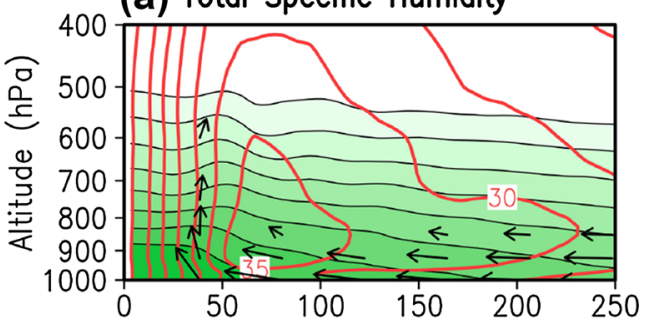

(b) $10 \&$ SCS \& MC

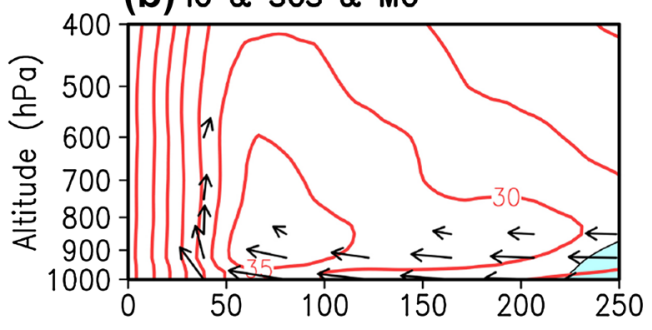

(c) PS

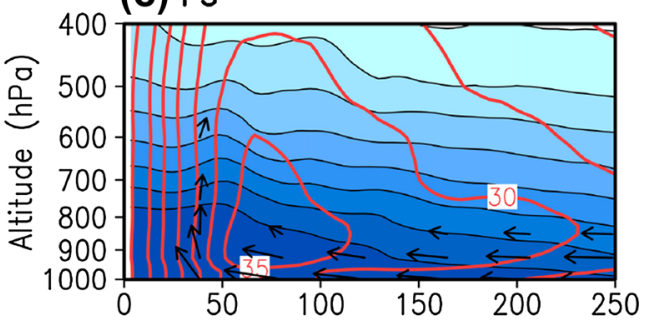

(d) ECS \& KS

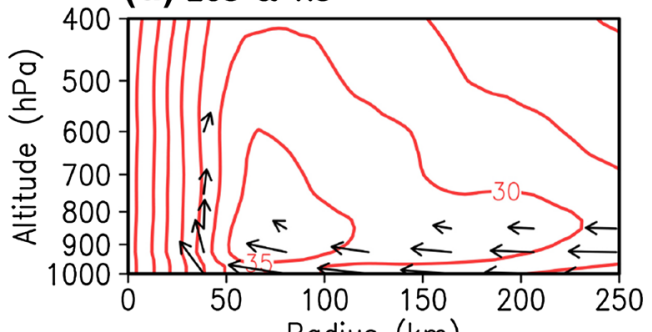

Radius (km)
O000UTC 14 July

(e) Total Specific Humidity

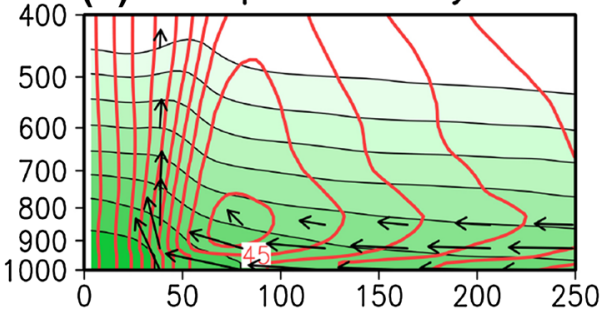

(f) $10 \&$ SCS \& MC

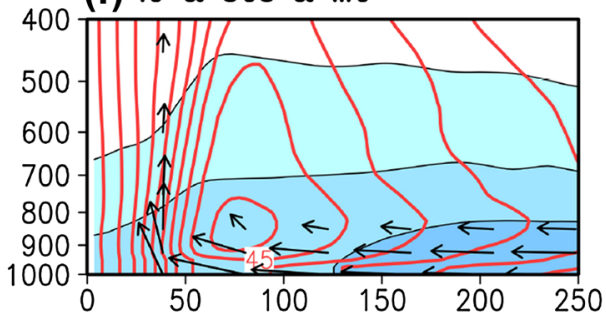

(g) PS

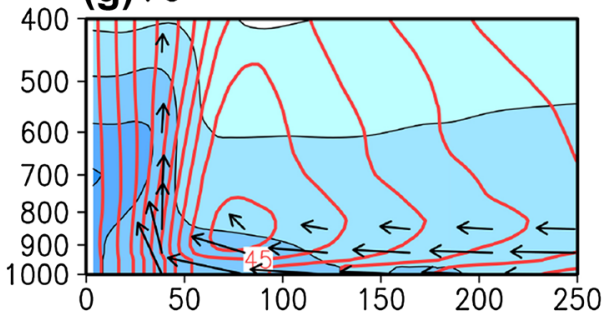

(h) ECS \& KS

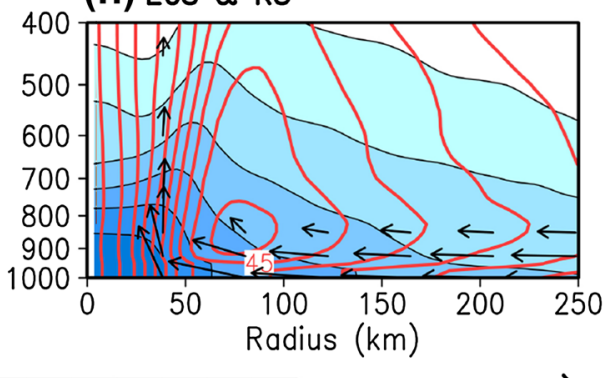

15 boundary layer, respectively. Also shown are the distributions of the inflow and outflow components of the radial wind at the two levels. We see the inflow area at the $900-\mathrm{hPa}$ level in the vicinity of the TC center at stage B (Fig. 11a), which corresponds to the prominence of the secondary TC circulation. Since low-level radial inflow is enhanced by TC development from stage B to D, the IO, SCS, and MC vapor that has been transported by the MCB can penetrate within the TC system accompanied by its secondary circulation (Fig. 11b). In contrast, at the $700-\mathrm{hPa}$ level, there is no apparent inflow in the vicinity of the TC center at stage B (Fig. 11c), thereby preventing the import of vapor of remote oceanic origins, which is distributed above the boundary layer into the
TC's inner region. Another notable indication is the outflow area extending northeastward from the TC center. This outflow becomes more evident at stage D (Fig. 11d), leading to the northeastward transport of the vapor above the boundary layer along the outflow. As a consequence, part of the IO, SCS, and MC vapor is transported toward southwestern Japan, which is consistent with the results shown in Fig. 8f. This causes the occurrence of heavy rainfall along the Pacific coast of western Japan (Hirata and Kawamura 2014). We can also see that the 700-hPa vapor increases slightly within the TC system at stage D. Such an increase may be attributed to the penetration of the vapor into the free atmosphere from the boundary layer by ascending motion. 
Fig. 11 (Upper panel) Magnified view of 900 -hPa radial winds (contours) and 900-hPa specific humidity (shaded) of Indian Ocean (IO), South China Sea (SCS), and Maritime Continent (MC) origins at a 0000UTC on July 12 and b 0000UTC on July 14. The shaded interval is $2 \mathrm{~g} \mathrm{~kg}^{-1}$. The blue (red) lines for radial winds denote inflow (outflow). The contour interval is $4 \mathrm{~m} \mathrm{~s}^{-1}$. Zero contours have been suppressed. (Lower panel) Magnified view of 700-hPa radial winds and 700-hPa specific humidity of $\mathrm{IO}, \mathrm{SCS}$, and MC origins at c 0000UTC on July 12 and d 0000UTC on July 14

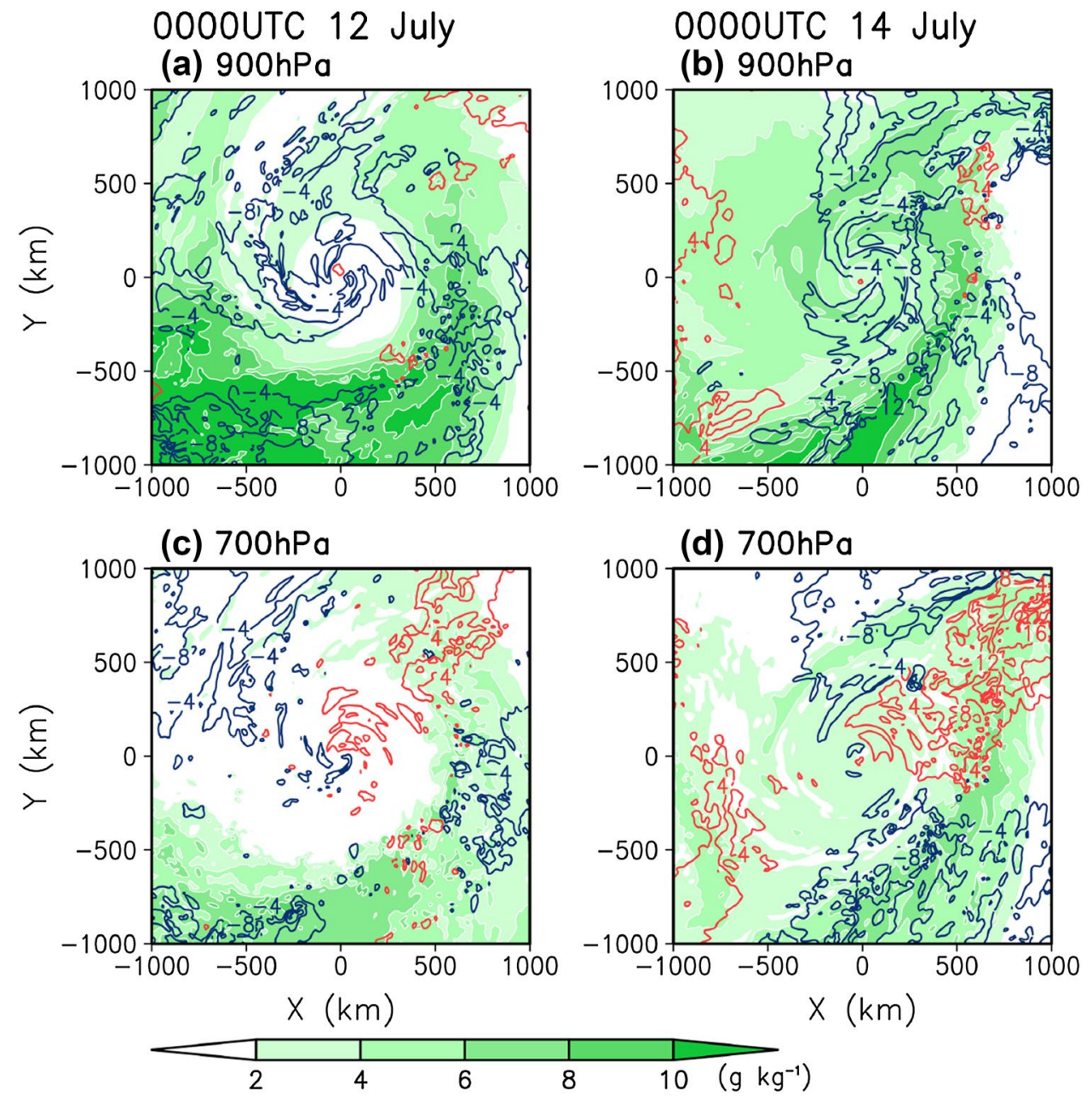

From the results of Figs. 10 and 11, we find that the IO, SCS, and MC vapor is remotely transported to the east of Man-yi via the MCB and is then imported into the cyclone's inner region through the boundary layer by the secondary TC circulation. We also anticipate that part of the vapor above the boundary layer in the MCB is transported toward the Pacific coast of southwestern Japan by the northeasterly outflow.

\section{Discussion}

As mentioned in the introduction, K2014 pointed out that, under the dominance of the South Asian monsoon westerlies, western North Pacific TCs can generate the MCB through the interaction of a Rossby wave response to TC-induced heating with the background flow, and that the formed MCB plays a vital role in transporting large amounts of vapor of remote ocean origin toward the vicinity of the TC center. H2016 has further conducted control experiments on the MCB formation and examined the change in the TC-MCB relationship in terms of its intensity and track. They found that the TC intensity at its mature phase becomes weak (strong) when the MCB is interrupted (well-defined) over the South China Sea. Thus, the findings of K2014 and H2016 suggest the presence of TC-MCB feedback.

However, one may wonder how remote ocean vapor is imported into the TC system and subsequently contributes to the TC's intensity. This study first tried to more precisely identify the proportion of each oceanic origin to the total precipitable water within the TC inner region using the isotopic regional spectral model (IsoRSM) (Yoshimura et al. 2010). As expected, K2014 underestimated the relative proportion of vapor from the underlying ocean to the total when Typhoon Man-yi is located over the East China Sea (ECS) and the Kuroshio (KS) region. This underestimation mainly arises from the use of both a two-dimensional global isotope circulation model (ICM) and global atmospheric reanalysis data. In this study, our simulation with the use of the IsoRSM, which can evaluate three-dimensional vapor transport, successfully captured the overall feature of the TC mesoscale structure. Thus, the proportion of each oceanic origin to the total precipitable water within the TC 
inner region is expected to have largely improved in comparison to that of K2014.

Despite such an improvement, it is noteworthy that Indian Ocean (IO), South China Sea (SCS), and Maritime Continent (MC) vapors still comprise a significant proportion of the total precipitable water within the TC inner region. As already indicated in Table 1, those vapors occupy approximately $23 \%$ at stage $\mathrm{D}$, which is comparable to approximately $27 \%$ Philippine Sea (PS) vapor and $28 \%$ ECS and KS vapors. Furthermore, condensation originating in remote oceans also exhibits a similar proportion to the total condensation, suggesting that remote ocean moisture actually contributes to the latent heat released within the TC inner region. As mentioned earlier, IO, SCS, and $\mathrm{MC}$ vapors, along with part of the PS vapor, are transported toward the TC by the MCB. The simulated MCB in this study tends to be somewhat weak as compared to that of H2016. This may be attributable to the weak bias of the TC intensity during its developing phase (stages A and B), as shown in Fig. 3b, because TC development is a necessary condition for the formation of the MCB. Thus, it is likely that the contribution of remote ocean vapor to the total precipitable water is underestimated in this study. Further improvement is required.

The remaining question is how the remote ocean vapor is imported into the TC inner region. As revealed in Figs. 8b and $11 \mathrm{a}, \mathrm{IO}, \mathrm{SCS}$, and MC vapors already reach the vicinity of the TC at stage B via the MCB. The next active player is the secondary TC circulation. Since the inflow of the radial wind, which is part of the secondary circulation, predominates within the atmospheric boundary layer (see Fig. 4), the accumulated remote ocean vapor can gradually penetrate into the TC system through the boundary layer. Such a feature can be confirmed in Figs. 10d and 11b. On the contrary, the import of remote ocean vapor above the boundary layer is not easy due to the absence of strong radial winds (Fig. 11c). Remote ocean vapor is imported into the TC's inner region through two dynamic processes: the first is large-scale vapor transportation via the MCB, and the second is the vapor's penetration due to inflow within the boundary layer in association with the secondary TC circulation. Since it takes a long time to undergo these two key processes, it appears that the influence of remote ocean vapor on the TC is delayed, as demonstrated by K2014.

As Man-yi intrudes from the PS sector into the ECS and KS sector, it consumes the accumulated PS vapor through the condensation process and, alternatively, receives an increased vapor supply from both the underlying ocean and the remote ocean. Of course, remote ocean vapor contains part of the PS vapor because it is persistently supplied toward the TC by the MCB. Total precipitable water within the TC system is sustained in this manner, contributing a great deal to the intensification and persistence of the TC.
As is well known, the maximum potential intensity (MPI) of the TC has been estimated often as a function of the sea surface temperature (SST) at the underlying ocean (e.g., DeMaria and Kaplan 1994; Baik and Paek 1998). However, our findings derived from this study suggest that substantial vapor import into the TC system from the surrounding ocean and the remote ocean has the potential to significantly interrupt the MPI-SST relationship. The proper evaluation and prediction of large-scale vapor import, such as the vapor transportation via the MCB highlighted in this study, might be useful for reducing significant errors in the prediction of TC intensity.

\section{Summary}

We have conducted a colored moisture analysis (CMA) using the isotopic regional spectral model (IsoRSM) for Typhoon Man-yi (2007) to evaluate the vapor import from the underlying ocean and the remote ocean into the TC system and to validate a positive feedback process between the TC intensity and the moisture conveyor belt (MCB) that has been suggested by previous studies (Kudo et al. 2014; Hegde et al. 2016). Although the stable oxygen isotope ratio $\left(\delta^{18} \mathrm{O}\right)$ data of precipitation observed on a daily basis was limited, we used the available $\delta^{18} \mathrm{O}$ data and confirmed that the IsoRSM has the ability to capture the basic nature of moisture transport in association with TCs. The track and intensity of the simulated Man-yi were comparable to those observed, and the mesoscale structure of the TC was also faithfully reproduced. The major findings in this study are briefly summarized as follows:

1. As Man-yi approaches southwestern Japan from the Philippine Sea (PS), it consumes the retained PS vapor through an active condensation process and, alternatively, compensates for the decrease in vapor with an increased vapor supply from both the underlying ocean and the remote ocean. Condensation of remote ocean vapors, such as Indian Ocean (IO), South China Sea (SCS), and Maritime Continent (MC) vapors, also occupies a significant proportion of the total condensation within the TC inner region during its mature phase.

2. IO, SCS, and MC vapors, including part of the PS vapor, are remotely transported to the east of Man-yi via the moisture conveyor belt (MCB). Accumulated remote ocean vapor gradually penetrates into the TC inner region through the atmospheric boundary layer due to the inflow of radial wind relevant to the secondary TC circulation. These two dynamic processes are prerequisites for the import of remote ocean vapor into the TC system. 
3. The influence of the remote ocean vapor on the TC is delayed because it takes time to undergo both largescale vapor transport via the MCB and vapor import into the TC inner region due to radial inflow within the boundary layer, which is consistent with Hegde et al. (2016), who found that changes in the TC intensity and track, which are regulated by the enhancement/weakening of the MCB, become evident at its mature phase. This study supports the hypothesis of the TC-MCB feedback process.

This study tried a new approach toward evaluating the vapor import into a western North Pacific TC from the remote ocean, using the IsoRSM. However, one serious problem is the shortage of daily $\delta^{18} \mathrm{O}$ data available. Further observations are required to validate the results of the IsoRSM. Sodemann et al. (2009), Sodemann and Stohl (2013), and Winschall et al. (2014) have examined the moisture origin and large-scale transport in association with extratropical cyclones over the North Atlantic region and extremely heavy flood events in Europe, using a water vapor tracer method. It would be worthwhile to compare their water vapor tracer method and our method with respect to TCs over the North Pacific and North Atlantic regions.

Although we used the IsoRSM with a horizontal resolution of $7 \mathrm{~km}$, higher-resolution simulations are necessary to reproduce the mesoscale structure of the TC more accurately. Previous research has pointed out that environmental relative humidity is one factor that controls the size of the TC (e.g., Wang 2009; Hill and Lackmann 2009), although we did not focus on the size of the TC in this study. If the TC-MCB feedback operates efficiently, it may also exert influence on the size of the TC because the remote ocean vapor constitutes part of the environmental relative humidity distribution. This issue will be examined in a separate paper. Of course, similar analyses should also be done for other western North Pacific TCs to clarify whether Typhoon Man-yi is a prototypical case or an extraordinary case in terms of the TC-MCB feedback process.

Acknowledgements Comments by the editor and anonymous reviewers were extremely helpful. The best track data for this paper are available at the RSMC Tokyo-Typhoon Center (http://www.jma. go.jp/jma/jma-eng/jma-center/rsmc-hp-pub-eg/RSMC_HP.htm). The JRA-55 data are available at the JRA-55 website (http://jra.kishou. go.jp/JRA-55/index_en.html). The NOAA OISST V2 data are available at the Earth System Research Laboratory website (http://www. esrl.noaa.gov/psd/data/gridded/data.noaa.oisst.v2.html). This research was supported by JSPS KAKENHI Grant Numbers 15K13569 and $16 \mathrm{H} 01846$

Open Access This article is distributed under the terms of the Creative Commons Attribution 4.0 International License (http:// creativecommons.org/licenses/by/4.0/), which permits unrestricted use, distribution, and reproduction in any medium, provided you give appropriate credit to the original author(s) and the source, provide a link to the Creative Commons license, and indicate if changes were made.

\section{References}

Baik JJ, Paek JS (1998) A climatology of sea surface temperature and the maximum intensity of western North Pacific tropical cyclones. J Meteor Soc Jpn 76:129-137

Braun SA (2006) High-resolution simulation of Hurricane Bonnie (1998). Part II: water budget. J Atmos Sci 63:43-64

Chou MD, Suarez MJ (1994) An efficient thermal infrared radiation parameterization for use in general circulation models. NASA Tech Memo 104606:84

DeMaria M, Kaplan J (1994) Sea surface temperature and the maximum intensity of Atlantic tropical cyclones. J Clim 7:1324-1334

Ek MB, Mitchell KE, Lin Y, Rogers E, Grunmann P, Koren V, Gayno G, Tarpley JD (2003) Implementation of Noah land surface model advances in the National Centers for Environmental Prediction operational mesoscale Eta model. J Geophys Res 108(D22):8851. doi:10.1029/2002JD003296

Fudeyasu H, Ichiyanagi K, Sugimoto A, Yoshimura K, Ueta A, Yamanaka MD, Ozawa K (2008) Isotope ratios of precipitation and water vapor observed in Typhoon Shanshan. J Geophys Res 113:D12113. doi:10.1029/2007JD009313

Hegde AK, Kawamura R, Kawano T (2016) Evidence for the significant role of sea surface temperature distributions over remote tropical oceans in tropical cyclone intensity. Clim Dyn 47:623-635

Hill KA, Lackmann GM (2009) Influence of environmental humidity on tropical cyclone size. Mon Weather Rev 137:3294-3315

Hirata H, Kawamura R (2014) Scale interaction between typhoons and the North Pacific subtropical high and associated remote effects during the Baiu/Meiyu season. J Geophys Res Atmos 119:5157-5170

Holland GJ (1995) Scale interaction in the Western Pacific monsoon. Meteor Atmos Phys 56: 57-79

Hong SY, Pan HL (1996) Nonlocal boundary layer vertical diffusion in a medium-range forecast model. Mon Weather Rev 124:2322-2339

Ichiyanagi K, Yoshimura K, Yamanaka MD (2005) Validation of changing water origins over Indochina during the withdrawal of the Asian monsoon using stable isotopes. SOLA 1:113-116

Jouzel J, Merlivat L (1984) Deuterium and oxygen 18 in precipitation: modeling of the isotopic effects during snow formation. J Geophys Res 87:11749-11757

Kanamaru H, Kanamitsu M (2007) Scale-selective bias correction in a downscaling of global analysis using a regional model. Mon Weather Rev 135:334-350

Kanamitsu M, Kanamaru H, Cui Y, Juang H (2005) Parallel implementation of the regional spectral atmospheric model. CEC Tech Rep: CEC-500-2005-014

Kanamitsu M, Yoshimura K, Yhang YB, Hong SY (2010) Errors of interannual variability and trend in dynamical downscaling of reanalysis. J Geophys Res 115:D17115. doi:10.1029/200 9JD013511

Kaplan J, DeMaria M (2003) Large-scale characteristics of rapidly intensifying tropical cyclones in the North Atlantic basin. Weather Forecast 18: 1093-1108

Katsube K, Inatsu M (2016) Response of tropical cyclone tracks to sea surface temperature in the western North Pacific. J Clim 29:1955-1975 
Kobayashi S, Ota Y, Harada Y, Ebita A, Moriya M, Onoda H, Onogi K, Kamahori H, Kobayashi C, Endo H, Miyaoka K, Takahashi K (2015) The JRA-55 reanalysis: general specifications and basic characteristics. J Meteor Soc Jpn 93:5-48

Kudo T, Kawamura R, Hirata H, Ichiyanagi K, Tanoue M, Yoshimura K (2014) Large-scale vapor transport of remotely evaporated seawater by a Rossby wave response to typhoon forcing during the Baiu/Meiyu season as revealed by the JRA-55 reanalysis. J Geophys Res Atmos 119:8825-8838

Kurihara Y (1975) Budget analyses of a tropical cyclone simulated in an axisymmetric numerical model. J Atmos Sci 32:25-59

Majoube M (1971a) Oxygen-18 and deuterium fractionation between water and steam. J Chim Phys Phys Chim Biol 68:1423-1436 (in French)

Majoube M (1971b) Fractionation in O-18 between ice and water vapor. J Chim Phys Phys Chim Biol 68:625-636 (in French)

Malkus J, Riehl H (1960) On the dynamics and energy transformations in steady-state hurricanes. Tellus 12:1-20

Merlivat L, Jouzel J (1979) Global climatic interpretation of the deuterium oxygen 18 relationship for precipitation. J Geophys Res 84:5029-5033

Moorthi S, Suarez MJ (1992) Relaxed Arakawa-Schubert: a parameterization of moist convection for general circulation models. Mon Weather Rev 120:978-1002

Rappaport EN et al. (2009) Advances and challenges at the National Hurricane Center. Weather Forecast 24: 395-419

Reynolds RW, Rayner NA, Smith TM, Stokes DC, Wang W (2002) An improved in situ and satellite SST analysis for climate. J Clim 15:1609-1625

Rios-Berrios R, Vukicevic T, Tang B (2014) Adopting model uncertainties for tropical cyclone intensity prediction. Mon Weather Rev 142:72-78

Slingo JM (1987) The development and verification of a cloud prediction scheme for the ECMWF model. Quart J Royal Meteor Soc 113:899-927

Sodemann H, Stohl A (2013) Moisture origin and meridional transport in atmospheric rivers and their association with multiple cyclones. Mon Weather Rev 141:2850-2868

Sodemann H, Wernli H, Schwierz C (2009) Sources of water vapour contributing to the Elbe flood in August 2002-a tagging study in a mesoscale model. Quart J Royal Meteor Soc 135:205-223
Stewart MK (1975) Stable isotope fractionation due to evaporation and isotopic exchange of falling water drops. J Geophys Res 80:1138-1146

Stohl A, Forster C, Sodemann H (2008) Remote sources of water vapor forming precipitation on the Norwegian west coast at $60^{\circ} \mathrm{N}$ - a tale of hurricanes and an atmospheric river. J Geophys Res 113:D05102. doi:10.1029/2007JD009006

Tanoue M, Ichiyanagi K, Yoshimura K (2016) Verification of the isotopic composition of precipitation simulated by a regional isotope circulation model over Japan. Isot Environ Health Stud. doi: 10.1080/10256016.2016.1148695

Tsuguti H, Kato T (2014) Objective extraction of heavy rainfall events and statistical analysis of their characteristic features. TENKI 61:455-469 (in Japanese)

Wang Y (2009) How do outer spiral rainbands affect tropical cyclone structure and intensity? J Atmos Sci 66:1250-1273

Wang Y, Wu CC (2004) Current understanding of tropical cyclone structure and intensity changes-a review. Meteor Atmos Phys $87: 257-278$

Winschall A, Pfahl S, Sodemann H, Wernli H (2014) Comparison of Eulerian and Lagrangian moisture source diagnostics-the flood event in eastern Europe in May 2010. Atmos Chem Phys 14:6605-6619

Yang MJ, Braun SA, Chen DS (2011) Water budget of Typhoon Nari (2001). Mon Weather Rev 139:3809-3828

Yoshimura K, Kanamitsu M (2008) Dynamical global downscaling of global reanalysis. Mon Weather Rev 136:2983-2998

Yoshimura K, Kanamitsu M (2009) Specification of external forcing for regional model integrations. Mon Weather Rev 137:1409-1421

Yoshimura K, Oki T, Ohte N, Kanae S (2004) Colored moisture analysis estimates of variations in 1998 Asian monsoon water sources. J Meteorol Soc Jpn 82:1315-1329

Yoshimura K, Kanamitsu M, Noone D, Oki T (2008) Historical isotope simulation using reanalysis atmospheric data. J Geophys Res 113:D19108. doi:10.1029/2008JD010074

Yoshimura K, Kanamitsu M, Dettinger M (2010) Regional downscaling for stable water isotopes: a case study of an atmospheric river event. J Geophys Res 115:D18114. doi:10.1029/2010JD014032 